\title{
Characterization and Antimicrobial Susceptibility of Aerococcus and Enterococcus Strains Isolated from Apical Periodontitis in Ouagadougou, Burkina Faso
}

\author{
Kaboré WAD ${ }^{* 1}$, Dembélé $\mathrm{R}^{1}$, Konaté $\mathrm{A}^{1}$, Leye Benoist $\mathrm{F}^{2}$, Seck $\mathrm{A}^{2}$, Touré $\mathrm{B}^{2}$, Boisramé $\mathrm{S}^{3}$, Traoré $A S^{1}$, Barro \\ $\mathrm{N}^{1}$ and Sangaré $\mathrm{L}^{4}$
}

${ }^{1}$ Laboratory of Molecular Biology, Epidemiology and Surveillance of Bacteria and Viruses Transmitted by Food (LaBESTA), Center for Research in Biological, Food and Nutritional Sciences (CRSBAN), Graduate School of Science and Technology (EDST), University of Ouaga I, Professor Joseph Ki-Zerbo, Burkina Faso ${ }^{2}$ Department of Odontology Conservative and Endodontics, University Cheikh Anta Diop of Dakar, Senegal ${ }^{3}$ University Laboratory of Biodiversity and Microbial Ecology, University of Western Brittany, France ${ }^{4}$ Laboratory of Bacteriology-Virology, University Hospital Yalgado Ouédraogo (CHU-YO), Training and Research Unit in Health Sciences (UFR/SDS), University of Ouaga I, Professor Joseph Ki-Zerbo, Burkina Faso

*Corresponding author: Wendpoulomdé Aimé Désiré Kaboré, Lecturer, Laboratory of Molecular Biology, Epidemiology and Surveillance of Bacteria and Viruses Transmitted by Food (LaBESTA), Center for Research in Biological, Food and Nutritional Sciences (CRSBAN), Graduate School of Science and Technology (EDST), Université Ouaga I Professeur Joseph Ki-Zerbo, 03 BP 7021 Ouagadougou 03, Burkina Faso, Fax: + 226 25300833, Tel: +226 70211283,E-mail: dr_kabore@yahoo.fr

Citation: Kaboré WAD, Dembélé R, Konaté A, Leye Benoist F, Seck A, et al. (2016) Characterization and Antimicrobial Susceptibility of Aerococcus and Enterococcus Strains Isolated from Apical Periodontitis in Ouagadougou, Burkina Faso. J Dent Oral Care Med 2(3): 301. doi: 10.15744/2454-3276.2.301

Received Date: June 07, 2016 Accepted Date: August 27, 2016 Published Date: August 29, 2016

\begin{abstract}
Backgroud: Apical periodontitis is caused by polymicrobial infection. The causative bacteria are generally organized into biofilms that adhere to the canal walls, and may include facultative bacteria such as Aerococcus and Enterococcus, which are the causative agents of several endodontic infections and have a natural resistance to many antibiotics including penicillin. This study aimed to investigate the involvement of these bacteria in diagnosed cases of apical periodontitis and determine their antibiotic resistance profiles.

Materials and Methods: Sixty-three patients diagnosed with apical periodontitis by a dental surgeon were included in the study. Samples were obtained from the root canals by aspiration and the exudates were subjected to standard microbiology methods according to the recommendations of the French Microbiology Society. Antimicrobial susceptibility was performed according to the method of Kirby-Bauer.

Results: In total, thirty-three bacterial strains were isolated from samples of affected root canals, of which 26 were Aerococcus (78.8\%) and 7 Enterococcus (21.2\%). Resistance of these strains to the antibiotics commonly used in endodontics gave the following pattern of resistance: amoxicillin-clavulanate (50\%), spiramycine (61.5\%), lincomycin (76.9\%), erythromycin (61.5\%) and amoxicillin (65.4\%).

Conclusion: Due to the high levels of antibiotic resistance found in the apical periodontitis causative strains, an epidemiological monitoring of antibiotic resistance is paramount. Developing countries, such as Burkina Faso, should make this a priority for their health development programs.
\end{abstract}

Keywords: Apical periodontitis; Aerococcus; Enterococcus; Antibiotics; Burkina Faso

\section{Introduction}

Endodontic infections are caused by multiple species of bacteria community, generally organized as biofilms adhering to the canal walls [1]. Approximately 700 bacterial species have been identified in the oral microbiome, although Enterococcus and Aerococcus are encountered very rarely [2]. These bacteria have been described as probable opportunistic pathogenic agents that can be isolated from a range of clinical endodontic specimens [3]. Jiang, et al. reported a severe odontogenic infection due to Aerococcus viridans [4]. Enterococcus has also been detected in the necrotic pulp [2]. Enterococcus faecalis is particularly difficult to remove during endodontic 
treatment. Indeed, it exists in the form of biofilms and, therefore, is more resistant to phagocytosis, antibodies and antimicrobial agents [5]. It is one of the most studied organisms in the field of endodontics [5]. Antibiotics are prescribed routinely by dental surgeons to treat as well as to prevent infections [6]. The technical procedure alone is often enough to solve the problem. But unfortunately this overabundance of prescription contributes to the development of resistance phenomena [6]. It is the same for self-medication, which is widespread in oral diseases and particularly in patients of a low socioeconomic status [7]. Yet low-income populations are most affected by oral-dental diseases [7]. African countries face many development challenges including that of oral health [8], thereby jeopardizing the effectiveness of antibiotics. Such studies have led to the discovery that many of these bacteria also have a natural resistance to penicillin, cephalosporin, clindamycin, and fluoroquinolones [2]. A large number of these bacterial species have, however, developed acquired resistance to other antibiotics [2]. The rapid emergence of antibiotic resistance is a major complicating factor in the treatment of infections, and it involves the dissemination of multiresistant strains [9]. Thus, the tremendous increase in the prevalence of resistance of Enterococcus and Aerococcus species underscores the need for a better understanding of the process of resistance as well as of the environment, so as to better define their ecology, epidemiology, and virulence in developing countries.

The aim of this study was to determine the prevalence and the antibiotic susceptibility of Enterococcus and Aerococcus strains found in cases of apical periodontitis in Burkina Faso, a major public health problem that has been grossly underestimated in many countries.

\section{Materials and Methods}

\section{Location, time, and nature of the study}

This was a prospective study performed over a period of five months from June to October of 2014 in Ouagadougou, Burkina Faso. Samples were collected at the Municipal Oral-Dental Health Center, Ougadougou (CMSBD) and the microbiology analyses were carried out at the Molecular Biology Laboratory for epidemiology and monitoring of food-borne bacteria and viruses (LaBESTA/ Centre de Recherche en Sciences Biologiques, Alimentaires et Nutritionnelles, CRSBAN) at the Ouaga I Professeur Joseph KiZerbo University in Burkina Faso.

\section{Study criteria}

Diagnostic criteria for apical periodontitis: Three key clinical criteria were used to make a diagnosis of apical periodontitis: the existence of a path for endodontic bacterial contamination; a negative response to tests of pulp vitality (performed using ice packaged in an anesthetic cartridge that had been emptied and filled with water); and the presence of pain that was provoked and exacerbated by touch, when the apical periodontitis was symptomatic. The presence of an apical protuberance that could be felt and/or the presence of a radio translucent endodontic bone image were also taken into account [10]. The grey or dark color of the crown was also noted. The patients were all examined by a dental surgeon.

Criteria for inclusion and non-inclusion: Only patients for whom a symptomatic or asymptomatic apical periodontitis was diagnosed were considered. The criteria for inclusion took into account the diagnosis of apical periodontitis for a permanent or decidual tooth in any patient.

The criteria for exclusion were the presence of a tooth that had already undergone endodontic treatment, the presence of a periodontal pocket of $5 \mathrm{~mm}$ or more, the presence of a fistula, and all cases of apical periodontitis involving a tooth for which the pulp chamber was exposed to the oral cavity (so as to eliminate all risk of contamination by exogenous bacteria).

\section{Experimental procedures}

Collection of the data and the samples: The data were collected using a form that allowed for compilation of information regarding personal details (e.g. age, gender, etc.), prior medical conditions, and the tooth in question. The level of oral-dental hygiene was assessed using the retention index of Björby and Löe [11]. The teeth involved were identified by a clinical examination, and documented further by retroalveolar radiography. An endobuccal connection was probed for using the sensor [9]. The four sides of the causal tooth were surveyed to measure the depth of a potential periodontal pocket. The income of the patients was assessed by assigning them to three categories of professions: patients with low incomes (e.g. farmers, students, pupils, and housewives), patients with high incomes (e.g. business people and private sector employees), and patients with moderate incomes (public sector employees, casual workers, retirees, and others). Following the clinical diagnosis, sampling was carried out according to the method of Rôcas and Siqueira with minor modifications [12]. Briefly, each patient rinsed their oral cavity for several seconds with a $0.12 \%$ chlorhexidine solution prior to the sampling. The crown and the lining were disinfected with a $2 \%$ chlorhexidine buffer to remove bacterial plaque. The samples (exudates) were obtained via the root canals in which a sterile rubber dam had been previously installed. Sterile paper tips that had been made to fit the canal were used to obtain the samples once the endodontic access cavity had been made using an endo access kit (Dentsply, USA). Sterile paper points No. 15 were introduced at the estimated working length for the removal of exudate. For an apical periodontitis abscess, the inflated mucosa was sanitized with a chlorhexidine buffer $2 \%$. Then, using a mounted sterile syringe, $2 \mathrm{~mL}$ of purulent exudate was aspirated at the mucosa inflated above the abscess. 
The exudate samples were immediately transferred to a sterile tube containing resazurine thioglycolate broth (Liofilchem, Italy). If the necrosis was dry and there was no exudate, $1 \mathrm{~mL}$ of resazurine thioglycolate was injected into the canal using a sterile syringe. This broth was mixed using a 15 file of appropriate working length, and the sample was taken using a sterile paper cone that was left in the canal for about 30 seconds. For a multi-rooted tooth, the sampling was performed in the canal in contact with the periapical infection. The exudate collected was immediately transferred to a sterile tube containing thioglycolate broth resazurin (Liofilchem, Italy). The tubes were placed at $4{ }^{\circ} \mathrm{C}$ in an ice chest and then immediately transported to the laboratory for microbiological analyses.

Isolation and identification of Aerococcus and Enterococcus: A 10 microliter aliquot of the transported broth was spotted onto Columbia agar supplemented with hemoglobin (Liofilchem, Italy) to probe for Aerococcus, and on Bile Esculine Azide (BEA) agar (bioMérieux, France) to probe for Enterococcus. After 48 to 72 hours of incubation at $37^{\circ} \mathrm{C}, 2$ to 3 colonies suspected of being Aerococcus (white-grey to greenish small-sized colonies) and Enterococcus (small translucent colonies surrounded by a black halo) were replated onto Mueller-Hinton agar (Liofilchem, Italy). After $18-24$ hours of incubation at $37^{\circ} \mathrm{C}$, biochemical identification was carried out using API 20 Strep strips (bioMérieux-France). The strips were read according to the manufacturer's recommendations and interpreted using APIWEB version V4.1 software (bioMérieux, France).

Antimicrobial susceptibility: The antibiograms were performed using a $0.5 \mathrm{McFarland}$ standard according to the agar disc diffusion method of Bauer, et al. [13]. After depositing the antibiotics, the plates were incubated at $37^{\circ} \mathrm{C}$ for 24 hours. The diameters of the antibiotic sensitivity halos were recorded according to the recommendations of the French Microbiology Society Antibiogram Committee (FMSAC) [14]. Twenty-one antibiotics were used: oxacillin (5 $\mu \mathrm{g})$, amoxicillin (30 $\mu \mathrm{g})$, amoxicillinclavulanic acid $(20+10 \mu \mathrm{g})$, cefotaxime $(30 \mu \mathrm{g})$, cefuroxime $(30 \mu \mathrm{g})$, cefixime $(5 \mu \mathrm{g})$, ceftriaxone $(30 \mu \mathrm{g})$, erythromycin $(15 \mu \mathrm{g})$, trimethoprime-sulfamethoxazole $(1.25 / 23.75 \mu \mathrm{g})$, chloramphenicol $(30 \mu \mathrm{g})$, gentamicin $(10 \mu \mathrm{g})$, tobramycine $(10 \mu \mathrm{g})$, netilmicin $(30 \mu \mathrm{g})$, piperacillin $(100 \mu \mathrm{g})$, piperacillin-tazobactam $(100+10 \mu \mathrm{g})$, metronidazole $(5 \mu \mathrm{g})$, penicillin $\mathrm{G}(10 \mathrm{IU})$, lincomycin $(15 \mu \mathrm{g})$, spiramycin $(100 \mu \mathrm{g})$, clindamycin $(10 \mu \mathrm{g})$, ciprofloxacin $(5 \mu \mathrm{g})$ (Liofilchem, Italy). The areas of inhibition were classified as either "resistant," "intermediate," or "sensitive" (FMSAC) [14].

Probing for broad-spectrum $\beta$-lactamases (BSBL): Strains that were resistant to $\beta$-lactams were subjected to investigation of BSBL activity according to the recommendations of the FMSAC [14]. A disk of amoxicillin-clavulanic acid and two disks of third generation cephalosporins (ceftriaxone and cefotaxime) were placed on the bacterial plate separated by a distance of 2 to $3 \mathrm{~cm}$ from one another. The presence of BSBL is indicated by a syngergetic effect between the disks, giving rise to an extended halo with the appearance of a "champagne cork" of keyhole.

Statistical analyses: Statistical analyses of the data were carried out using Sphinx Plus 5 software (Park Altai’s 74650 Chavannes, France). Joint analyses (bivariate) and $\chi^{2}$ (Chi-squared) test were used to compare two qualitative variables. Differences were considered to be significant when $p<0.05$.

\section{Results}

\section{Characteristics of the patients}

In total, 63 patients were seen in the setting of medical consultations. Forty-one consulted in regard to acute apical periodontitis (65.1\%) and twenty-two for chronic apical periodontitis $(34.9 \%)(p=0.0167)$. As $50.8 \%$ of the total, the 19-41 years old age group was the most strongly represented in our population. This population was comprised of $57.1 \%$ male patients versus $42.9 \%$ females $(p=0.2568)$ (Table 1$)$.

\begin{tabular}{|c|c|c|c|c|c|c|}
\hline \multirow{2}{*}{ Sex } & \multicolumn{5}{|c|}{ Age group (years) } & \multirow{2}{*}{$\begin{array}{c}\text { TOTAL N } \\
(\%)\end{array}$} \\
\cline { 2 - 6 } & $7-12$ & $13-18$ & $19-40$ & $41-60$ & $\geq 60$ & $36(57.1)$ \\
\hline Male & $0(0)$ & $3(4.8)$ & $18(28.6)$ & $12(19)$ & $3(4.8)$ & $36(42.9)$ \\
\hline Female & $1(1.6)$ & $7(11.1)$ & $14(22.2)$ & $5(7.9)$ & $0(0)$ & $27(4)$ \\
\hline TOTAL N (\%) & $1(1.6)$ & $10(15.9)$ & $32(50.8)$ & $17(27)$ & $3(4.8)$ & $63(100)$ \\
\hline
\end{tabular}

Table 1: Apical periodontitis cases according to age group and gender

The repartition of the patients according to their wealth corresponded to three approximately equally sized groups. That is to say, the patients with low incomes represented $38.1 \%$, those with moderate incomes $31.8 \%$, and those with high incomes $30.2 \%(p=0.7)$.

Poor oral hygiene was noted for $79.4 \%$ of the patients who were assigned a score of $3(p=0.0001)$. Tartar deposits were pronounced with a strong inflammation of the gums $(p=0.0001)$. Eleven patients received a score or 2 , while a score of 1 was assigned to only two patients. Reviewing case histories did not yield any significant findings in regard to prior medical conditions. Indeed, $81 \%$ of the patients ignored their prior medical histories $(p=0.0001)$. Self-medication (started on the day of the consultation), however, was used by $39.7 \%$ of the patients $(p=0.1014)$. The most widely used agents were amoxicillin $(15.9 \%)$, ampicillin $(14.3 \%)$, and paracetamol (3.2\%). The central incisors of the upper jaw were the teeth that were involved the most often (57.1\%). 


\section{Prevalence of the isolated microbes}

Thirty samples were positive for Aerococcus and Enterococcus (47.6\%). In total, 33 strains were isolated, of which 26 were Aerococcus $(78.7 \%)$ and 7 Enterococcus (21.3\%) ( $p=0.0009)$ (Table 2). The identified species were: Aerococcus viridans [24 (72.7\%)], Aerococcus urinae [2 (6.1\%)], Enterococcus avium [4 (12.1\%)] and Enterococcus faecium [3 (9.1\%)] (Table 3). Aerococcus viridans was the main species isolated $(72.7 \%)$, and its involvement in acute apical periodontitis was significant $(p=0.0001)$. Four cases of co-infection (6.3\%) were noted. One case of acute apical periodontitis involved Enterococcus faecium and Enterococcus avium, and another such case involved Enterococcus faecium and Aerococcus viridans. One case of chronic apical periodontitis involved Aerococcus urinae and Enterococcus avium, and another such case involved Enterococcus avium and Aerococcus viridans.

\begin{tabular}{|c|c|c|c|}
\hline \multirow{2}{*}{$\begin{array}{c}\text { Apical } \\
\text { Periodontitis }\end{array}$} & \multicolumn{2}{|c|}{ Bacterial genus n (\%) } & \multirow{2}{*}{$\begin{array}{c}\text { TOTAL N } \\
\text { (\%) }\end{array}$} \\
\hline & Aerococcus & Enterococcus & \\
\hline Acute & $19(57.5)$ & $3(9.1)$ & $22(66.6)$ \\
\hline Chronic & $7(21.2)$ & $4(12.2)$ & $11(33.4)$ \\
\hline Total N (\%) & $26(78.7)$ & $7(21.3)$ & $33(100)$ \\
\hline
\end{tabular}

Table 2: Distribution of bacterial genus according to the infectious stage

\begin{tabular}{|c|c|c|c|c|c|}
\hline \multirow{2}{*}{$\begin{array}{c}\text { Apical } \\
\text { Periodontitis }\end{array}$} & \multicolumn{4}{|c|}{ Bacterial species isoles $\mathbf{n}(\%)$} & \multirow{2}{*}{$\begin{array}{c}\text { TOTAL N } \\
(\%)\end{array}$} \\
\hline & $\begin{array}{c}\text { Aerococcus } \\
\text { viridans }\end{array}$ & $\begin{array}{c}\text { Aerococcus } \\
\text { urinae }\end{array}$ & $\begin{array}{c}\text { Enterococcus } \\
\text { avium }\end{array}$ & $\begin{array}{c}\text { Enterococcus } \\
\text { faecium }\end{array}$ & \\
\hline Acute & $18(54.5)$ & $1(3)$ & $2(6.1)$ & $1(3)$ & $22(66.6)$ \\
\hline Chronic & $6(18.2)$ & $1(3)$ & $2(6.1)$ & $2(6.1)$ & $11(33.4)$ \\
\hline Total N (\%) & $24(72.7)$ & $2(6)$ & $4(12.2)$ & $3(9.1)$ & $33(100)$ \\
\hline
\end{tabular}

Table 3: Distribution of bacterial species according to the infectious stage

\section{Antibiotic sensitivity profile}

The Aerococcus strains exhibited resistance to the following antibiotics that were tested: metronidazole (100\%), cefixime (76.9\%), cefuroxime $(76.9 \%)$, cefotaxime $(76.9 \%)$, oxacillin $(76.9 \%)$, lincomycin $(76.9 \%)$, trimethoprime-sulfamethoxazole $(88.5 \%)$, ceftriaxone $(84.6 \%)$, and penicillin $(80.8 \%)$ (Table 4$)$.

\begin{tabular}{|c|c|c|c|c|c|}
\hline \multirow{2}{*}{\multicolumn{3}{|c|}{ Antibiotics }} & \multicolumn{3}{|c|}{ Aerococcus sensitivity to antibiotics N (\%) } \\
\hline & & & \multirow{2}{*}{$\begin{array}{c}\text { Resistant } \\
13(50) \\
\end{array}$} & \multirow{2}{*}{$\begin{array}{c}\text { Intermediate } \\
0(0)\end{array}$} & \multirow{2}{*}{$\begin{array}{c}\text { Sensitive } \\
13(50)\end{array}$} \\
\hline \multirow{10}{*}{$\beta$-lactams } & \multirow{6}{*}{ Penicillins } & Amoxicillin-clavulanic acid & & & \\
\hline & & Amoxicillin & $17(65.4)$ & $0(0)$ & $9(34.6)$ \\
\hline & & Penicillin G & $21(80.8)$ & $0(0)$ & $5(19.2)$ \\
\hline & & Piperacillin & $13(50)$ & $0(0)$ & $13(50)$ \\
\hline & & Piperacillin-tazobactam & $11(42.3)$ & $0(0)$ & $15(57.7)$ \\
\hline & & Oxacillin & $20(76.9)$ & $0(0)$ & $6(23.1)$ \\
\hline & \multirow{4}{*}{$\begin{array}{l}\text { Cephalo- } \\
\text { sporins }\end{array}$} & Ceftriaxone & $22(84.6)$ & $0(0)$ & $4(15.4)$ \\
\hline & & Cefixime & $20(76.9)$ & $0(0)$ & $6(23.1)$ \\
\hline & & Cefuroxime & $20(76.9)$ & $0(0)$ & $6(23.1)$ \\
\hline & & Cefotaxime & $20(76.9)$ & $1(3.8)$ & $5(19.2)$ \\
\hline \multicolumn{2}{|c|}{ Phenicols } & Chloramphenicol & $17(65.4)$ & $0(0)$ & $9(34.6)$ \\
\hline \multicolumn{2}{|c|}{ Quinolones } & Ciprofloxacin & $12(46.2)$ & $4(15.4)$ & $10(38.5)$ \\
\hline \multicolumn{2}{|c|}{ Sulfamides } & Trimethoprime-sulfamethoxazole & $23(88.5)$ & $0(0)$ & $3(11.5)$ \\
\hline \multicolumn{2}{|c|}{ Nitro-imidazols } & Metronidazole & $26(100)$ & $0(0)$ & $0(0)$ \\
\hline \multirow{3}{*}{\multicolumn{2}{|c|}{ Aminosids }} & Gentamycin & $2(7.7)$ & $2(7.7)$ & $22(84.6)$ \\
\hline & & Tobramycin & $14(53.8)$ & $2(7.7)$ & $10(38.5)$ \\
\hline & & Netilmicin & $10(38.5)$ & $6(23.1)$ & $10(38.5)$ \\
\hline \multirow{2}{*}{\multicolumn{2}{|c|}{ Macrolides }} & Erythromycin & $16(61.5)$ & $3(11.5)$ & $7(26.9)$ \\
\hline & & Spiramycin & $16(61.5)$ & $5(19.2)$ & $5(19.2)$ \\
\hline \multirow{2}{*}{\multicolumn{2}{|c|}{ Lincosamides }} & Clindamycin & $16(61.5)$ & $2(7.7)$ & $8(30.8)$ \\
\hline & & Lincomycin & $20(76.9)$ & $2(7.7)$ & $4(15.4)$ \\
\hline
\end{tabular}

Table 4: Sensitivity of Aerococcus isolated from apical periodontitis 
On the other hand, they exhibited a good level of sensitivity to gentamycin (84.6\%). As for the Enterococcus strains, they were resistant to: metronidazole (100\%), cefixime (85.7\%), ceftriaxone (71.4\%), and cefuroxime (71.4\%). Yet they exhibited a good level of sensitivity to amoxicillin-clavulanic acid (85.7\%), ciprofloxacin (85.7\%), amoxicillin (85.7\%), gentamycin (71.4\%), and piperacillin 5 (71.4\%) (Table 5). No Aerococcus or Enterococcus strains produced BSBL.

\begin{tabular}{|c|c|c|c|c|c|}
\hline \multirow{2}{*}{\multicolumn{3}{|c|}{ Antibiotics }} & \multicolumn{3}{|c|}{ Aerococcus sensitivity to antibiotics N (\%) } \\
\hline & & & \multirow{2}{*}{$\begin{array}{c}\text { Resistant } \\
1(14.3)\end{array}$} & \multirow{2}{*}{$\begin{array}{c}\text { Intermediate } \\
0(0)\end{array}$} & \multirow{2}{*}{$\begin{array}{c}\text { Sensitive } \\
6(85.7)\end{array}$} \\
\hline \multirow{10}{*}{$\beta$-lactams } & \multirow{6}{*}{ Penicillins } & Amoxicillin- clavulanic acid & & & \\
\hline & & Amoxicillin & $1(14.3)$ & $0(0)$ & $6(85.7)$ \\
\hline & & Penicillin G & $3(42.9)$ & $0(0)$ & $4(57.1)$ \\
\hline & & Piperacillin & $2(28.6)$ & $0(0)$ & $5(71.4)$ \\
\hline & & Piperacillin-tazobactam & $4(57.1)$ & $0(0)$ & $3(42.9)$ \\
\hline & & Oxacillin & $6(85.7)$ & $0(0)$ & $1(14.3)$ \\
\hline & \multirow{4}{*}{$\begin{array}{l}\text { Cephalo- } \\
\text { sporins }\end{array}$} & Ceftriaxone & $5(71.4)$ & $0(0)$ & $2(28.6)$ \\
\hline & & Cefixime & $6(85.7)$ & $0(0)$ & $1(14.3)$ \\
\hline & & Cefuroxime & $5(71.4)$ & $0(0)$ & $2(28.6)$ \\
\hline & & Cefotaxime & $4(57.1)$ & $1(14.3)$ & $2(28.6)$ \\
\hline \multicolumn{2}{|c|}{ Phenicols } & Chloramphenicol & $4(57.1)$ & $0(0)$ & $3(42.9)$ \\
\hline \multicolumn{2}{|c|}{ Quinolones } & Ciprofloxacin & $1(14.3)$ & $0(0)$ & $6(85.7)$ \\
\hline \multicolumn{2}{|c|}{ Sulfamides } & Trimethoprime-sulfamethoxazole & $4(57.1)$ & $3(42.9)$ & $0(0)$ \\
\hline \multicolumn{2}{|c|}{ Nitro-imidazols } & Metronidazole & $7(100)$ & $0(0)$ & $0(0)$ \\
\hline \multirow{3}{*}{\multicolumn{2}{|c|}{ Aminosids }} & Gentamycin & $2(28.6)$ & $0(0)$ & $5(71.4)$ \\
\hline & & Tobramycin & $2(28.6)$ & $1(14.3)$ & $4(57.1)$ \\
\hline & & Netilmicin & $2(28.6)$ & $3(42.9)$ & $2(28.6)$ \\
\hline \multirow{2}{*}{\multicolumn{2}{|c|}{ Macrolides }} & Erythromycin & $2(28.6)$ & $3(42.9)$ & $2(28.6)$ \\
\hline & & Spiramycin & $3(42.9)$ & $1(14.3)$ & $3(42.9)$ \\
\hline \multirow{2}{*}{\multicolumn{2}{|c|}{ Lincosamides }} & Clindamycin & $4(57.1)$ & $0(0)$ & $3(42.9)$ \\
\hline & & Lincomycin & $3(42.9)$ & $1(14.3)$ & $3(42.9)$ \\
\hline
\end{tabular}

Table 5: Sensitivity of Enterococcus isolated from apical periodontitis

\section{Discussion}

In terms of the teeth involved, the central incisors of the upper jaw were found to be the most affected by apical periodontitis (57.1\%). In contrast, a prior study in France found that molars (78\%), followed by premolars (15\%) were involved the most in endodontic inflammatory lesions [15]. The front teeth play an important role in the physical appearance of facial features. Concerns in regard to esthetics could underlie the predominance of the upper jaw incisors in the present study.

The occurrence of apical periodontitis in patients appeared to be linked with poor oral-dental hygiene. Similar studies have also noted a correlation between apical periodontitis and poor oral-dental hygiene. The low level of education of the patients could explain the lack of adherence to oral-dental hygiene guidelines, thus promoting the emergence of pathogenic bacteria [16,17].

Of the 33 strains isolated in this study, the predomiant bacterial strain was Aerococcus viridans and its involvement in acute apical periodontitis was significant. A similar study that was carried out to characterize the potential virulent microbial strains involved in apical periodontitis isolated 59 microbial strains belonging to 28 bacterial species, including Aerococcus and Enterococcus [18]. The natural habitat of Aerococcus viridans is essentially the environment [19]. This bacterium is often seen as the source of nosocomial infections and, although not part of the oropharyngeal flora, was isolated in odontogenic infections [4]. Long confused with Streptococcus or Staphylococcus and described as such because of their very similar cultural and morphological characteristics, this germ has been scarcely reported in the literature [20]. A study in Tunisia noted the involvement of Enterococcus in oral infections [21].

The Aerococcus strains exhibited elevated resistance to metronidazole, trimethoprime-sulfamethoxazole, ceftriaxone, penicillin, cefixime, cefuroxime, cefotaxime, oxacillin, and lincomycin. On the other hand, they exhibited good sensitivity toward gentamycin. As for the Enterococcus strains, they were resistant to metronidazole, cefixime, ceftriaxone, and to cefuroxime. Yet they exhibited good sensitivity to amoxicillin-clavulanic acid, ciprofloxacin, amoxicillin, gentamycin, and piperacillin.

As shown by prior studies, the antibiotic resistance profiles of Aerococcus changed rapidly. Until the 1980s, this bacterium was considered to be sensitive to the most commonly used antibiotics at that time, but a recent study has demonstrated that these strains exhibit resistance not only to penicillin, but also to chloramphenicol and antibiotic quinolones [22]. Furthermore, another 
has shown that Enterococcus strains exhibit a disconcerting degree of resistance to ampicillin (100\%), amoxicillin-clavulanic acid (100\%), ciprofloxacin (100\%), clindamycin (100\%), chloramphenicol (100\%), streptomycin (100\%), gentamicin (100\%), rifampicin (100\%), erythromycin (100\%), and teicoplanin (100\%) [20]. Fifty-seven percent of these enterococci were resistant to three of the five classes of antibiotics that were tested. Hence, this indicates the presence of multiresistant Enterococcus strains in a hospital environment [23]. Another study, however, has shown that Enterococcus strains are sensitive to ampicillin and amoxicillin [24]. Thus, resistance to antibiotics could be induced by selective pressure due to inappropriate and extended use of antibiotics [25]. The resistance could otherwise be explained by the presence of virulence and antibiotic resistance genes, which can be transferred to other bacteria in biofilms [24]. Other studies have confirmed the resistance of opportunistic pathogens due to the presence of resistance genes [26-28]. Several studies have reported findings in regard to the use of antibiotics in the revascularization of immature permanent teeth that exhibit either acute or chronic apical periodontitis [29]. Ciprofloxacin, metronidazole and minocyclin are the group of antibiotics that are most commonly used. Thus, this combination of antibiotics is deposited locally in the canal of the treated tooth [29]. Saber and Hadi have reported in regard to the possible local use of antibiotics to eradicate endocanal bacteria, although this needs to be preceded by an antibiogram [30]. Such local use could sensitize bacteria and lead to the development of resistance.

\section{Conclusion}

In this study, Aerococcus strains are the most resistant. Aerococcus viridans is the main species that was isolated. Poor oral-dental health is the most significant risk factor. Teaching of and adherence to oral hygiene guidelines should limit the occurrence of apical periodontitis. Aside from specific circumstances where it is medically warranted, the prescription of antibiotics is not always of use with endodontic apical pathologies. Careful evaluation of their need would limit the danger of increasing antibiotic resistance. In Aerococcus infection, gentamycin is alternative antibiotic. Amoxicillin, ciprofloxacin, amoxicillin-clavulanic acid and gentamycin are alternative antibiotics Enterococcus infection. Given multidrug resistance observed, susceptibility testing before antibiotic treatment will guide the control of antibiotic prescription. This, with basic rules of oral hygiene will improve the care of patients.

\section{Ethical Considerations}

Following approval of the research protocol by the ethics committee(s) of Burkina Faso, all samples, as well as the epidemiological data, were obtained with informed patient consent.

\section{References}

1. Ricucci D, Siqueira JF (2010) Biofilms and apical periodontitis: study of prevalence and association with clinical and histopathologic findings. J Endod 36: 1277-88.

2. Carrero C, González MC, Martínez MA, Varona FS, Ortega HD, et al. (2014) Low frequency of Enterococcus faecalis in the oral mucosa of subjects attending dental consultation. Rev Fac Odontol Univ Antioq 26: 261-70.

3. Gilmore MS, Lebreton F, Schaik VW (2013) Genomic transition of enterococci from gut commensals to leading causes of multidrug-resistant hospital infection in the antibiotic era. Curr Opin Microbiol 16: 10-6.

4. Jiang X, Shoukang Yang S, Guoliang Sun G (2013) Odontogenic Infection Due to Aerococcus viridans. J Oral Maxillofac Surg 71: $1552-4$.

5. Rezende GC, Massunari L, Queiroz IOA, Filho JEG, Jacinto RC, et al. (2016) Antimicrobial action of calcium hydroxide-based endodontic sealers after setting, against E. faecalis biofilm. Braz Oral Res 30: e38.

6. Oberoi SS, Dhingra C, Sharma G, Sardana D (2015) Antibiotics in dental practice: how justified are we. Int Dent J 65: 4-10.

7. Jaiswal AK, Pacahva S, Sanikommu S, Rawlani SS, Pydi S, et al. (2015) Dental pain and self care: a cross sectional study of people with low socio-economic status residing in rural India. Int Dent J 65: 256-60.

8. Hescot P, China E, Bourgeois D, Maina S, Monteiro da Silva O, et al. (2013) The FDI African Strategy for Oral Health: addressing the specific needs of the continent. Int Dent J 63: 113-20.

9. Costelloe C, Metcalfe C, Lovering A, Mant D, Hay AD, et al. (2010) Effect of antibiotic prescribing in primary care on antimicrobial resistance in individual patients: systematic review and meta-analysis. BMC 340: c2096.

10. Lasfargues JJ (2001) Le diagnostic clinique des parodontites apicales. Réal Clin 12: 149-62.

11. Björby A, Löe H (1967) The relative significance of different local factors in the initiation and development of periodontal inflammation. J Periodontal Res 2 : 76-7.

12. Rôcas IN, Siqueira JF (2013) Detection of antibiotic resistance genes in samples from acute and chronic endodontic infections and after treatment. Arch Oral Biol 58: 1123-8.

13. Bauer AW, Kirby WMM, Sherries JC, Turck M (1966) Antibiotic susceptibility testing by a standardized single disk method. Am J Pathol 45: 493-6.

14. Comité de l’Antibiogramme de la Société Française de Microbiologie (CASFM) (2012) Recommandation 2012.

15. Touré B, Azogui-Lévy S, Dzara I, Azérad J, Boucher Y (2011) Qualité des traitements endodontiques dans un échantillon de patients consultant en urgence dans le service d'odontologie du GHPS. Rev Odont Stomat 40: 280-92.

16. Chu CH, Ho PL, Lo EC (2012) Oral health status and behaviours of preschool children in Hong Kong. BMC Public Health 12: 767.

17. Celepkolu T, Toptanci IR, Bucaktepe PGE, Sen V, Dogan MS, et al. (2014) A microbiological assessment of the oral hygiene of 24-72-month-old kindergarten children and disinfection of their toothbrushes. BMC Oral Health 14: 94.

18. Cristea AD, Marutescu L, Chifiriuc MC, Lazăr V, Suciu I, et al. (2014) Virulence profiles of microbial strains isolated from patients with chronic apical lesions. Proc Rom Acad Series B 16: 25-31. 
19. Chen LY, Yu WC, Huang SH, Lin ML, Chen TL, et al. (2012) Successful treatment of Aerococcus viridans endocarditis in a patient allergic to penicillin. J Microbiol Immunol Infect 45: 158-60.

20. Kerbaugh MA, Evans JB (1968) Aerococcus viridans in the Hospital Environment. Appl. Microbiol 16: 519-23.

21. Kouidhi B, Zmantar T, Mahdouani K, Hentati H, Bakhrouf A (2011) Antibiotic resistance and adhesion properties of oral Enterococci associated to dental caries. BMC Microbiol 11: 1471-80.

22. Augustine T, Thirunavukkarasu, Bhat BV, Bhatia BD (1994) Aerococcus viridans endocarditis. Mayo Clin Proc 59: 47-8.

23. Shehabi AA, Badran EF, Alnasra NA (2014) The emergence of antimicrobial resistance in enterococci isolates from infants: A review study. Int Arabic J Antimicrob agents 4: 1-7.

24. Dahlen G, Blomqvist S, Almstahl A, Carlén A (2012) Virulence factors and antibiotic susceptibility in enterococci isolated from oral mucosal and deep infections. J Microbiol 4: 10.

25. Martín V, Vela AI, Gilbert M, Cebolla J, Goyache J, et al. (2007) Characterization of Aerococcus viridans isolates from swine clinical specimens. J Clin Microbiol 45: 3053-7.

26. Foucault ML, Depardieu F, Courvalin P, Grillot-Courvalin C (2010) Inducible expression eliminates the fitness cost of vancomycin resistance in enterococci. Proc Natl Acad Sci 107: 16964-9.

27. Rigottier-Gois L, Alberti A, Houel A, Taly JF, Palcy P, et al. (2011) Largescale screening of a targeted Enterococcus faecalis mutant library identifies Envelope fitness factors. PLoS ONE 6: e29023.

28. Comerlato CB, Resende MCC, Caierão J, d’Azevedo PA (2013) Presence of virulence factors in Enterococcus faecalis and Enterococcus faecium susceptible. Mem Inst Oswaldo Cruz, Rio de Janeiro 108: 590-5.

29. Nosrat A, Seifi A, Asgary S (2011) Regenerative Endodontic Treatment (Revascularization) for Necrotic Immature Permanent Molars: A Review and Report of Two Cases with a New Biomaterial. JOE 4: 562-7.

30. Saber SEDM, Hady SAE (2012) Development of an intracanal mature Enterococcus faecalis biofilm and its susceptibility to some antimicrobial intracanal medications; an in vitro study. Eur J Dent 6: 43-50.

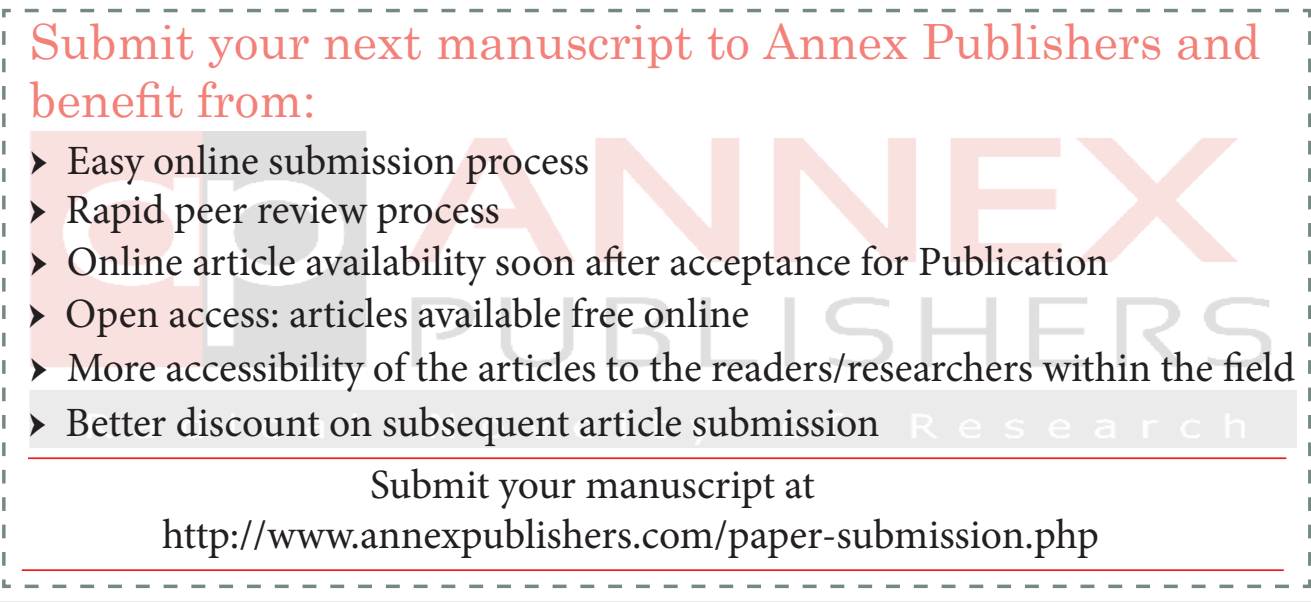

